\title{
STORAGE OF TROPICAL FRUITS
}

\author{
BY Dr. C. W. WARDLAW, \\ IMPerial College of Tropical Agriculture, Trinidad
}

W HEN work was begun at the Trinidad Low Temperature Research Station in 1928*, the immediate problem was to ascertain the keeping and carrying quality of the several banana varieties and hybrids which might be used as substitutes for the Gros Michel (the principal variety of commerce), then threatened by the epidemic spread of Panama disease. Within a few years, however, the very general use to which the Station could be put was recognized both by local agricultural administrations and by shipping companies operating in the Caribbean region, and by request work was in turn extended to tomatoes, limes, grapefruit, oranges, avocados, mangoes, papaws, pincapples, melongenes, cucurbits of various kinds, and to the assortment of vegetables that can be grown in the tropics. To some of these commodities a considerable amount of study has been devoted, and their general cold-storage requirements have now been ascertained with a sufficient degree of precision for practical purposes.

Success in transporting fruits and vegetables does not depend on refrigeration alone, and to a large extent it has fallen to those engaged on storage problems in the tropics to investigate, at least in part, related biological aspects such as the physiological behaviour of different varieties, questions of harvesting maturity, optimum conditions for harvesting, pre-storage and disinfectant treatments, the effect of different methods of wrapping and packing, post-storage treatments including ripening technique, and wastage problems in general. In the following notes some account is given of results obtained in Trinidad and of the varied botanical problems encountered in investigating the storage requirements of tropical fruits.

If not held at suitably low temperatures, the ripening of tropical fruits and the onset of wastage take place very rapidly. The practical problem, accordingly, is primarily one of arresting or retarding ripening without injuring the fruit. To do this satisfactorily, it is essential that rapid cooling to the required storage temperature should be undertaken as soon after harvesting as possible.

If an arbitrary and incomplete distinction may be drawn between 'cool' storage and 'cold' storage, it will be found that the greater number of tropical fruits require to be carried in 'cool' storage (for cxample, avocados, $45^{\circ} \mathrm{F}$. ; mangoes and tomatoes, $47 \cdot 5^{\circ} \mathrm{F}$.; grapefruit, oranges and limes, $45^{\circ}$ to

* Funds were provided by the former Empire Jarketing Board. $50^{\circ} \mathrm{F}$.; Gros Michel bananas, $53^{\circ} \mathrm{F}$.; Congo and Lacatan bananas, $56^{\circ}$ to $58^{\circ} \mathrm{F}$. ; papaws, $60^{\circ} \mathrm{F}$., etc.), if chilling injuries are to be avoided. In that exposure to too low a temperature may result in physiological injuries such as superficial blemishing, failure to ripen, and loss of resistance to fungal pathogens already present in the tissues as latent or dormant infections, it will be apparent that the temperatures selected for the storage and transport of tropical fruits should allow of a sufficient margin of safety to avoid the danger of chilling. Indeed of recent years there has been a growing tendency to raise the storage temperatures recommended, this having been especially marked in the case of grapefruit, where 'pitting' (chill blemishing) has in the past constituted a large proportion of the wastage; thus whereas formerly temperatures below $40^{\circ} \mathrm{F}$. were generally employed, the present tendency is to store fruit at $45^{\circ}$ to $50^{\circ} \mathrm{F}$., and even higher temperatures have been advocated.

Both in respect of the normal physiology of the fruit and the biology of its pathogens, the maintenance of correct humidity relationships within storage rooms or holds is of very considerable importance. This conclusion is drawn from a number of instances in which the questions of humidity and water-relations have presented themselves for consideration ; it must be admitted, however, that no final statement of the exact conditions required in different instances can yet be made. But, in general, it may be said of relative humidity $(a)$ that it should not be so low as to allow of serious loss in weight or modify the appearance and maturation of the fruit during the storage period; (b) that it should not be so high as to promote the superficial growth of fungal hyphx; and (c) that localized condensation within the cargo stack must be avoided. The question of the need for improved humidity control is now being urged on all sides by biologists ; in its physical and manipulative aspects it is also being closely studied by physicists and engineers, and there seems little doubt that the future will be marked by interesting and valuable innovations.

\section{BANANAS}

During the past decade, the major aspect of banana investigations has centred around the search for a variety to replace the Gros Michel or Jamaica banana. This variety, which suffers from the 
disadvantage of being highly susceptible to Panama disease, is in all other respects almost uniquely suited to the conditions of bulk stowage and transport required in the extensive Caribbean industry; symmetry of bunch, disposition and size of fingers, uniformity of growth, toughness of skin, resistance to disease and ability to be carried at a temperature sufficiently low to effect a substantial control of fungal wastage, combine to make it not easily replaceable by other varieties. Investigations on the keeping quality of possible substitutes have chiefly served to accentuate the collective advantages possessed by the Gros Nichel and the difficulties of obtaining a comparable assemblage in an immune variety. A note of optimism may be sounded regarding certain hybrids which have been obtained in Trinidad by crossing a wild, seeded variety (BIusa acuminata) with the Gros Michel. These combine resistance to Panama disease and to Cercospora leaf disease with a very considerable assemblage of the desirable qualities of the Gros Michel. The first hybrid obtained, known as I.C.1, is open to criticism because it yields occasional seeds. The second, known as I.C.2, is seedless; it possesses many of the desirable Gros Michel characters and has good texture and flavour, but the individual fruits tend to be rather short.

Several interesting results have accrued from recent bulk storage trials. When the I.C.2 banana is grown under favourable conditions, it is capable of yielding good bunches, as judged by the appearance, symmetry and weight of individual fingers, 9-, 8- and 7-hand bunches, suitable for export, being represented among the collection of fruit obtained from different parts of Trinidad. While the symmetry of the bunch as a whole and the disposition and shape of individual fingers are admittedly not so good as in the Gros Michel, nevertheless the hybrid I.C.2 possesses qualities which would make it commercially important in the event of any major failure of the Gros Michel. Its present value as a source of food among the local peasantry should not be overlooked. In relation to current storage and ripening procedure for bananas, the optimum harvesting maturity lies between ' $\frac{3}{4}$-full' and 'heavy $\frac{3}{4}$-full', using Gros Michel standards of grading. 'Thin' grade fruit is difficult to ripen; 'heavy $\frac{3}{4} \cdot$ full' fruit, which behaves well during cold storage at $53^{\circ} \mathrm{F}$, , ripens with an excessive odour of pear drops. The Gros Nichel transport temperature of $53^{\circ} \mathrm{F}$., with rapid cooling to that temperature, is well suited to this hybrid.

It is generally agreed that the ideal hybrid banana of the future is likely to be one derived from the Gros Michel as female parent. Whether or not the I.C.2 eventually becomes acceptable as a commercial banana, any data which can be collected on its growth in the field and physiology in storage will contribute materially towards the central object of this work, that is, the maintenance of supplies of fruit of good quality.

During recent years the epidemic spread of Cercospora leaf disease in the Caribbean region has necessitated a renewal of storage trials with the Gros Michel banana. As a result of this disease many bunches undergo premature ripening while they are still attached to the plant. In storage trials it has been ascertained that the behaviour of fruit obtained from plantations which have been more or less severely infected by Cercospora musce is abnormal in several respects ; the pulp is of a slight to well-marked buff or pale ochraceoussalmon colour, fruit tends to ripen prematurely, to chill during the period of refrigerated transport, and to ripen with undesirable rapidity when removed to a higher temperature. Moreover, as a result of the extensive leaf destruction caused by C. musa, bunches tend to grow slowly and to remain of small size; hence fruit may actually be considerably more mature than is indicated by its appearance, and departures from the normal storage bchaviour for that grade may be anticipated.

\section{LIMES}

The storage of limes exemplifies in particular the importance of the humidity factor. In general, limes are more difficult to handle than lemons, being less cold resistant and, because of their small size, more subject to wastage through shrivelling; the avoidance of desiccation, indeed, is one of the major problems in handling this fruit, a loss in weight of 12-14 per cent being accompanied by severe shrivelling. As loss in weight under tropical conditions may amount to $1 \cdot 5-2 \cdot 0$ per cent per day, the commercial storage life, as limited by the onset of shrivelling, may be seriously curtailed by undue delay whilst fruit is waiting to be graded and packed. Speedy handling, protecting of fruits by suitable wrappers, and rapid cooling to $45^{\circ} \mathrm{F}$. are essential to the successful storage of this commodity.

The susceptibility of the West Indian lime to wither-tip disease has necessitated the breeding of new varieties. By crossing the Philippine lime with the West Indian variety a number of hybrids highly resistant to wither-tip have been obtained. One of these, known as the T.I lime, is a fruit of good appearance, juice and oil-content and is now being cultivated and marketed on a not inconsiderable scale. A second hybrid, T.6, possesses less farourable commercial qualities, but has proved of interest when studied with the T.1 hybrid and the parental types. Under identical 
JULy 29, 1939, Vor.. 144

storage conditions, all four exhibit considerable differences in respect of loss in weight; weight for weight and grade for grade, the two hybrids are subject to more rapid desiccation than either of the parents. With regard to cold-resistance, the Philippine lime proved most resistant and the hybrid T'.6 least; the hybrid T.1, on the other hand, is apparently more cold-resistant than the West Indian lime. Such variations are interesting in that they afford an indication of the rearrangement of physiological characters which may result from hybridization.

As with other kinds of citrus fruits, limes are very subject to the superficial blemishing known as oleocellosis which results from mechanical injury to turgid fruits. To aroid oleocellosis, fruits should not be picked too early in the morning or too soon after the fruits have been covered with dew or rain water.

\section{Grapefruits}

Because of the rapidly increasing importance of grapefruit as an orchard crop in the West Indies, an extensive programme of investigations has been carried out. Although data were available from experiments conducted in the United States, South Africa, and elsewhere, it was imperative, because of the relation between environment and keeping quality, to study Trinidad fruit entirely on its merits. In particular, attention has been directed to ascertaining the effect of time of harvesting, duration of the quailing or curing period prior to handling, the precise temperatures suitable for short or more prolonged periods in storage, the nature and incidence of chilling, the avoidance of excessive desiccation and the incidence and control of wastage. The behaviour of fruit derived from trees which has suffered from gummosis and root-rot also presented special problems of both practical and academic interest. Various commercial practices, for example, ethylene colouring, borax treatment, etc., which in some countries have now become standardized, when applied to Trinidad grapefruit have yielded results other than those expected. Thus when fruit is treated with borax solution before crating, as a means of controlling blue and green moulds-which, as a fact, are of minor importance in Trinidad-the effect of the fungicide is to promote the activities of the fungus Colletortich um gloesporiodes, which is already present within the tissues as latent infections, so that severe wastage may result. A similar effect is produced by the use of iodized wraps. Striking variations in the keeping quality, susceptibility to chilling and to fungal disease in fruit from different localities in Trinidad have also become apparent in studies conducted over a number of years.

\section{Avocados}

The avocado, which is native to Central America, is represented in the West Indies by a very considerable range of types. The majority of trees are of seedling origin and so far only a few have been selected, named and used in the propagation of standard types. The influence of environment and genetical constitution on physiological behaviour during storage is well shown by the avocado, such information as was available from investigations undertaken in America being inapplicable to fruit grown under Trinidad conditions.

Cultivated avocados are generally referred to three horticultural races, the Mexican, the Guatemalan and the West Indian, useful types being fixed and propagated by budding and grafting. Seedling avocados of the third group as grown under West Indian conditions are characterized by a low fat content, great variation in all fruiting characters, and by their comparative intolerance of cold-storage conditions (most varieties show chilling injury when held at temperatures below $50^{\circ} \mathrm{F}$. $\left(10^{\circ} \mathrm{C}\right.$.) ). A distinctive feature of the avocado is its high fat content. It has been ascertained that fruit grown in Trinidad, and presumably elsewhere under moist tropical conditions, has a considerably lower oil content than that produced in Florida and California. In Trinidad, this low oil content, which is apparently largely determined by environmental factors, is characteristic of introduced as well as of local varieties.

Experimental observations indicate that the striking variability in fruiting characters of West Indian avocados is closely paralleled by the range in behaviour exhibited by fruits when subjected to refrigerated or gas storage or to a combination of both. In the avocado, maturation slowly continues even at relatively low temperatures, so that fruits ultimately become ripe. In varieties not sufficiently cold resistant, the metabolic trend is, however, abnormal, and chill effects in due course become apparent in a darkening of the rascular strands and storage parenchyma, the initiation of such changes being closely associated with the onset of ripening. As only a small number of varieties combine the requisite commercial qualities with adequate cold resistance. the practical problem is essentially one of selection.

\section{MANGoes}

In investigating the storage of mangoes, it has been necessary not only to select from the very considerable number of named and seedling varieties available for study, but also to consider such diverse aspects as criteria of harresting maturity in the several varieties, and the effect of 
season and environment on keeping quality and liability to wastage. A finding of interest to horticulturists is the very marked effect that environment may exercise on the productivity and keeping quality of different varieties. Thus, whereas the Julie variety crops well and gives a fairly good storage life when grown under the moist conditions that prevail in Trinidad, the Peter's variety is of uncertain productivity and is very susceptible to fungal rotting; on the other hand, the Peter's (Pairi or Bombay) variety, as grown under the dry conditions found in certain areas in Jamaica, yields export fruit of excellent quality.

Like many other tropical fruits, mangoes are readily subject to low-temperature injury. Chilling may be manifested in several ways, including the production of definite skin blemishes, failure to develop normal colour on ripening, failure to ripen on removal from cold storage, and a notable decline in resistance to the inroads of pathogens. Susceptibility to chilling varies with variety, maturity at harvesting and season. Trinidad experience indicates that mango varieties in general are subject to chilling injury if exposed to temperatures below $48^{\circ}-50^{\circ} \mathrm{F}$., superficial blemishing being accentuated by partial desiccation.

The wastage problem in mango storage is serious. Apart from damage due to wound parasites (which is inconsiderable in carefullyhandled fruit) the majority of fruits, though apparently free from disease, nevertheless carry latent infections of several important pathogens. Wastage attributable to such latent infections is greatly accentuated by chilling, slow ripening and tardy distribution of ripe fruit. The high incidence of field infections directs attention to the need for careful consideration of orchard sanitation, and it is evident that questions of spacing, pruning, spraying and upkeep generally should be made subjects of special study.

\section{PAPAWS}

The papaw (Carica papaya) may be cited as an example of a tropical crop where little progress can be made in the matter of commercial cold storage until standardized supplies of fruit are made available as a result of horticultural research. The papaw is well known as the source of the digestive substance papain, obtained by coagulating the latex exuded from green fruits on wounding. During recent years some attention has been paid to this fruit as a possible export crop notably in South Africa and the West Indies. An attempt has also been made to extend papaw cultivation in California and to breed varieties adapted to prolonged storage or transport. From the information available on the production and cold-storage behaviour of this fruit, it may be predicted that the organization and standardization of an export industry will be attended with serious difficulties.

The papaw shows great variety in its fruiting characters, some types producing small spherical fruits no larger than an orange, while others have elongated fruits as large as a watermelon and weighing up to $25 \mathrm{lb}$. In working towards an export trade, standardized production is a first essential; the basic problem is, therefore, to select and perpetuate good types from material which is notoriously variable. Again, as most varieties are diccious, the liability to a low standard of production is accentuated by the number of male plants present in a sowing.

Storage trials carried out in Trinidad have shown that relatively immature papaws will not ripen after cold storage, and further, that most of the varietics tested show evidence of chilling if held at temperatures lower than $55^{\circ}-60^{\circ} \mathrm{F}$.

\section{TOMATOES}

Tropically-grown tomatoes may be mentioned as illustrating the unexpected in storage investigations. Thus it has been ascertained that fruits of several varieties grown under Trinidad conditions have yielded storage records which compare very favourably with those obtained elsewhere. When picked full-grown but green, Trinidad fruit can be kept in cold storage at $40^{\circ}-47^{\circ} \mathrm{F}$. for twenty to thirty days, and on remoral to a higher temperature remains in good condition for a further eight to ten days. These results have been confirmed over a number of years and are in marked contrast to the rapid degeneration recorded in comparable storage trials with fruit grown outside the tropics. In view of the disparity between Trinidad findings and previous English results, storage trials were undertaken at the Low Temperature Research Station, Cambridge, in which supplies of glasshouse fruit grown during summer and autumn respectively were used; the summer fruit gave results comparable to those obtained in Trinidad; the autumn fruit, on the other hand, was characterized by the poorer keeping quality already mentioned. As to why summer-grown fruit or that obtained under tropical conditions should be more tolerant of low temperatures is not understood.

During recent years the terms of the grant from the Colonial Development Fund by which this Station is maintained include a concentration on fundamental research with special reference to the banana. 